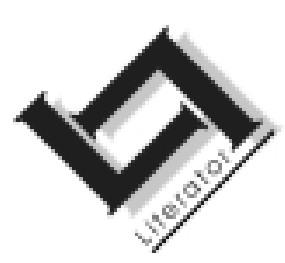

\title{
Die waarde van kognitiewe semantiek in die analisefase van vertaling
}

\author{
Marné Pienaar \\ Departement Linguistiek en Literatuurwetenskap \\ Randse Afrikaanse Universiteit \\ AUCKLANDPARK \\ E-pos: mpi@Iw.rau.ac.za
}

\section{Abstract}

The value of cognitive semantics in the analysis phase of translation

One of the most challenging tasks facing the trainee translator relates to the analysis phase of translation. If the analysis is inadequate it is unlikely that the subsequent translation will be acceptable. This article takes Cognitive Semantics as point of departure and focuses on the theoretical aspects of force dynamics (Talmy, 1985 and 2000) by indicating that the understanding of schematic categories and schematic meaning does not only contribute to the pre-translation analysis phase in the translation process but could also enhance the understanding of the process per se. Force dynamics is discussed in relation to subjectification, perspective and grounding. It is argued that the principles of force dynamics are applicable to the way in which the translator should approach a text in the analysis phase.

The principles of force dynamics are illustrated by making use of the short story "Voorgevoel" by John Miles. The text is in the first instance analysed by placing the focus on the role of the narrator as conceptualiser. Subsequently, the working of force dynamics in the texts is discussed. Finally it is indicated how the principles of force dynamics also act as metaphor for the process of translation as such.

\section{Opsomming}

Die waarde van kognitiewe semantiek in die analisefase van vertaling

Een van die grootste uitdagings waarmee 'n aspirantvertaler te kampe het, hou verband met die analisefase van vertaling. Indien die analise onvoldoende is, is dit onwaarskynlik dat die daaropvolgende vertaling aanvaarbaar sal wees. In hierdie artikel word die Kognitiewe Semantiek as vertrekpunt geneem en word gefokus op die teoretiese 
aspekte van kragdinamika (Talmy, 1985 en 2000) ten einde aan te dui dat die begrip van skematiese kategorieë en skematiese betekenis nie alleen 'n bydrae kan lewer in die voorvertalinganalisefase van die vertalingsproses nie, maar ook kan bydra tot begrip van die proses as sodanig. Kragdinamika word bespreek teen die agtergrond van subjektifikasie, perspektief en begronding. Die aanname dat die beginsels van kragdinamika van toepassing is op die wyse waarop die vertaler 'n teks behoort te benader in die analisefase word in dié artikel beredeneer.

Die beginsels van kragdinamika word geïllustreer aan die hand van die kortverhaal "Voorgevoel" deur John Miles. Die teks word in die eerste instansie geanaliseer deur die fokus te plaas op die rol van die verteller as konseptualiseerder. Die optrede van kragdinamika in die teks word vervolgens bespreek. Ten slotte word aangedui hoe die beginsels van kragdinamika ook as metafoor kan dien vir die vertaalproses as sodanig.

\section{Inleiding: die analise van die bronteks}

Een van die grootste uitdagings wat 'n aspirantvertaler van literêre tekste in die gesig staar, hou verband met die analise van die bronteks. 'n Swak analise lei bykans sonder uitsondering tot 'n swak vertaling. Newmark (1995:11) wys byvoorbeeld daarop dat die vertaalproses in die eerste instansie begin met die lees van 'n teks en wel om twee redes: eerstens om te verstaan waaroor dit handel, en tweedens om dit vanuit ' $n$ vertaler se perpektief te analiseer. Die analise is onder meer daarop gerig om die intensie van die teks te agterhaal. Volgens Newmark is die intensie van ' $n$ vertaler gewoonlik dieselfde as dié van die outeur van die oorspronklike bronteks (Newmark, 1995:12). Hieruit volg dit dus dat 'n vertaler 'n intieme kennis van die outeursintensie moet hê ten einde dit wat die outeur in gedagte gehad het, akkuraat te kan weergee. Daar moet egter in gedagte gehou word dat Newmark gewoonlik as 'n voorstander van die ekwivalensiebenadering tot vertaling gesien word en dat die terme akkuraat en ekwivalent kontensieus binne die veld van vertaalteorie is (vgl. Kenny, 2001:77-80 vir 'n opsommende bespreking van verskillende standpunte oor ekwivalensie).

Ander benaderings tot vertaling, soos die funksionele benadering of skoposteorie plaas ook klem op 'n deeglike analise van 'n teks alvorens met die vertaling begin word. Monday (2001:82) wys byvoorbeeld daarop dat Nord se Text Analysis in Translation primêr daarop gerig is om aan studente in vertaalkunde 'n model van bronteksanalise te gee wat van toepassing is op alle tekstipes en vertaalsituasies. In Nord se latere werke val die klem veral op die 
vertaalopdrag, die rol van die bronteksanalise en die funksionele hiërargie van vertaalprobleme. Een van die vrae wat 'n vertaler haarself volgens Nord se model reeds moet afvra wanneer die vertaalopdrag bestudeer word, hou verband met die vraag: Waarom is die bronteks geskryf en hoekom word dit vertaal? Hierdie vraag slaan dus weer op die intensie van die outeur en daarmee saam ook die intensie van die vertaler.

Die intensie van die oorspronklike outeur hou egter verband met 'n bepaalde perspektief en alhoewel die vertaler daarna streef om die outeursintensie te agterhaal en die perspektief van die outeur in die vertaling te reflekteer, bly dit 'n subjektiewe proses. In dié verband sê Bush (2001:127) die volgende:

Literary translation is the work of literary translators. That is a truism which has to serve as a starting point for a description of literary translation, an original subjective activity at the centre of a complex network of social and cultural practices. The imaginative, intellectual and intuitive writing of the translator must not be lost to the disembodied abstraction which is often described as 'translation'.

Die opmekaarplasing of passing van die oorspronklike outeur en die vertaler se perspektiewe is egter nie sonder probleme nie. Veral in literêre tekste waar faktore soos tydsgees en wêreldbeeld 'n belangrike aspek van ' $n$ teks vorm, is die uitdaging wat aan die vertaler gestel word besonder veeleisend en kan dit net met sukses aangepak word indien die teks deeglik geanaliseer word (vgl. Potgieter, 2003:39 e.v. vir 'n bespreking van die impak wat periodisering op die vertaler het).

Ervaring het egter geleer dat die analise van literêre tekste met die oog op die vertaling daarvan, veral vir aspirantvertalers (studente), besonder moeilik is. Konsepte soos perspektief en subjektifikasie word dikwels vaag hanteer en studente vind dit problematies om die verskil tussen hulle eie perspektiewe en dié van outeurs raak te sien. Hierdie tipe probleme lei dan tot 'n vlak van vertalersubjektiwiteit wat die kwaliteit van vertalings drasties en negatief beïnvloed.

Een manier waarop dié konsepte aan studente verduidelik kan word en wat prakties aan hulle gedemonstreer kan word, is deur gebruik te maak van beskrywingsraamwerke van die kognitiewe linguistiek en spesifiek die kognitiewe semantiek waar konsepte soos subjektifikasie, perspektief en begronding sentraal staan. 


\section{Kognitiewe linguistiek}

In haar artikel, "Image in translation: a case study of three Polish Hamlets", maak Tabakowska (1997:3) die stelling dat die Kognitiewe Linguistiek (KL) belowende perspektiewe inhou vir vertaalkunde in dié sin dat dit enersyds die gaping tussen letterkundige studies en die linguistiek kan oorbrug en tweedens dat dit moontlikhede bied vir 'n koherente teoretiese raamwerk vir 'n oorkoepelende vertaalteorie. Dit volg op 'n vroeëre ondersoek (Tabakowska, 1993:128) waarin sy onder meer tot die gevolgtrekking kom dat vertaalekwivalensie hoogstens kan dui op ' $n$ ekwivalensie in die (lees)ervaring van deelnemers waar die term "deelnemers" verwys na die lesers van die oorspronklike teks (en die vertaler is hierby ingesluit) enersyds, en lesers van die vertaalde teks andersyds. Alhoewel dié ervaring op lesersresepsie dui, sluit ervaringsekwivalensie noodwendig ook ervaring voor teksresepsie, naamlik 'n prekonseptuele ervaringstruktuur of konseptualiseringskapasiteit in. Om dus te sê dat 'n oorspronklike en 'n vertaalde teks ekwivalent is, impliseer die ekwivalente status van twee konseptualiserings. Die bereiking hiervan is egter nie so eenvoudig nie aangesien konseptualisering die resultaat is van ervaring en gevolglik sou ' $n$ mens dus moet aanvaar dat vertaalekwivalensie slegs kan volg op ekwivalensie in ervaring. Dit kan egter selde die geval wees - ervaring verskil wat betref individue, maatskaplike groepe, taalgemeenskappe en so meer. Nieteenstaande die feit dat konseptuele stelsels verskil, is die konseptualiseringskapasiteit van die mens egter universeel en word dit gedeel deur sprekers van alle tale. Daar is nie 'n beperking op die moontlikheid om te verstaan nie en verskille tussen individuele konseptuele stelsels tree nie noodwendig as struikelblokke op nie. Wat wel problematies is vanuit ' $n$ vertalersperspektief, is die oorkartering van konsepte en ervaring in 'n ander taal. Volgens Tabakowska (1993:129) is 'n nie-ekwivalente vertaling gevolglik óf die resultaat van 'n gebrek aan begrip deur die vertaler, óf as gevolg van 'n objektiewe onmoontlikheid om die gaping tussen twee verskillende konseptuele stelsels (tale) te oorbrug.

Dit is veral die eerste moontlikheid wat hier van belang is. ' $n$ Vertaling kan nie suksesvol wees as die bronteks nie verstaan word nie. ' $n$ Deeglike analise van die teks is onontbeerlik. Dit is egter een ding om te sê dat 'n teks geanaliseer moet word, maar hoe moet die aspirantvertaler die analise aanpak? Vervolgens sal beredeneer word dat een moontlike vertrekpunt vir so 'n analise 'n duidelike begrip van konseptualisering behels. ' $n$ Vertaler moet 
begin deur die outeur en haar eie rol as konseptualiseerder te verstaan.

Een van die primêre aannames van die $\mathrm{KL}$ is dat taal ' $\mathrm{n}$ weerspieëling van ' $n$ mens se werklikheidsbelewing is. Dit gaan in die besonder om die rol van die konseptualiseerder: taal verwoord bloot dit wat deur die individu gekonseptualiseer word. Hieruit ontwikkel die konsep subjektifikasie (Langacker, 1990:5) waarvolgens elke individu subjektief vanuit sy eie beheersende punt na die wêreld om hom/haar kyk.

\subsection{Die begrip subjektifikasie}

Subjektifikasie hou onder meer in dat 'n uitdrukking se betekenis nie gereduseer kan word tot 'n objektiewe kenmerk van 'n beskryfde situasie nie: die wyse waarop die konseptualiseerder die situasie konstrueer en vir kommunikasiedoeleindes uitbeeld, moet in ag geneem word. Langacker (1994:1) omskryf betekenis vanuit 'n kognitiewe raamwerk soos volg: "Meaning is identified with conceptualization (i.e. mental experience) which compromises not only conceptual content but the construal of that content". 'n Uitdrukking se presiese semantiese waarde word bepaal deur verskeie konstruksie-aspekte, waaronder die vlak van spesifiekheid waardeur die situasie gekenmerk word, agtergrondaannames en -verwagtings, die relatiewe prominensie wat aan verskeie entiteite toegesê word en die perspektief van waaruit na die situasie gekyk word (vgl. Langacker, 1990:5). Die semantiese waarde van 'n uitdrukking word dus bepaal deur die volledige spektrum van aspekte (of semantiese domeine) wat die konteks van die uitdrukking vorm.

Daar is reeds vroeër daarop gewys dat 'n vertaler by 'n eerste lees van 'n bronteks die teks lees met die oog daarop om betekenis en die intensie van die teks (en die outeur) te agterhaal. Langacker (2002:3) wys daarop dat betekenis vanuit 'n kognitiewe hoek, in die eerste instansie verband hou met konseptualisering (of mentale ervaring). Dit sluit sensoriese en motoriese ervaring asook die spreker se konsepsie van die sosiale, kulturele en linguistiese konteks in. Hy wys ook daarop dat daar nie 'n duidelike begrensing tussen linguistiese en buite-linguistiese kennis kan wees nie. As vertrekpunt vir betekenis roep 'n uitdrukking 'n reeks oop konsepsies op wat op een of ander manier verband hou met die entiteit waarop dit dui. Enige faset van die kennis (dit wat oor die entiteit bekend is), mag op 'n gegewe punt van belang wees vir 'n spesifieke linguistiese doelwit. Betekenis is volgens hom absoluut afhanklik van ons 
kapasiteit om dieselfde situasie op verskillende maniere te konseptualiseer. Hierdie konseptualisering maak egter die moontlikheid oop dat uitdrukkings wat dieselfde objektiewe situasie en dieselfde konseptuele inhoud oordra, nietemin semanties heelwat kan verskil. Dit is natuurlik presies die probleem waarvoor die aspirantvertaler te staan kom en moet oorbrug. Dit is haar taak om seker te maak dat die vertaalde teks juis nie semanties verskil van die oorspronklike nie. In hierdie verband behoort kennis van die wyse waarop taalkragdeterminante funksioneer, moontlik 'n nuttige instrument te wees in die analise van 'n literêre teks.

\subsubsection{Subjektifikasie en taalkragdeterminante}

Johnson (1987:51-53; vgl. ook Gibbs, 1999:45) wys daarop dat sekere gestalts of beeldskemas in terme waarvan konsepte beskryf word, terugherleibaar is na die mens se herhaalde belewing van kragte in sy/haar interaksie met sy omgewing. (Dit gaan dus steeds oor die mens se belewing van sy/haar bestaanswerklikheid en dus subjektifikasie.) Hierdie kragdinamiese aspekte is net so basies as wat deiktiese oriëntasie is. Talmy (2000:10) omskryf taalkragdeteminante soos volg:

Force dynamics covers the range of relations one entity can bear to another with respect to force. This range includes one entity's intrinsic force tendency, a second entity's opposition to that tendency, the first entity's resistance to such opposition, and the second entity's overcoming of such resistance. It further includes the presence, absence, imposition, or removal of blockage of one entity's intrinsic force tendency by a second entity. In force dynamics, causation thus now appears within a larger conceptual framework in systematic relationship to such other concepts as permitting and preventing, helping and hindering.

Sewe verskillende tipes kan hiervolgens (vgl. ook Talmy, 1985 en Strydom, 1994:33) onderskei word, naamlik:

- Kompulsie: Hierdie beeldskema verteenwoordig die inwerking van 'n krag waarteen die individu hom skynbaar nie kan verset nie.

- Blokkasie: In 'n poging om kragdadig met dinge en mense om te gaan, kom daar dikwels struikelblokke voor wat die krag stuit.

- Teenwerkende krag: Twee ewe sterk kragte kom teen mekaar te staan met die gevolg dat nie een van die kragte verder kan beweeg nie. 
- Afwyking: As gevolg van toevallige interaksie tussen twee of meer kragte verander die rigting van die krag.

- Verwydering van versperring: 'n Struikelblok word uit die weg geruim en gee gevolglik vrye toegang.

- Potensiële krag: Hierdie beeldskema is van toepassing op kragte wat potensieel geaktiveer kan word.

- Aantrekkingskrag: Dit dui op kragte soortgelyk aan gravitasie wat daartoe lei dat iets deur iets anders aangetrek word.

Bostaande gestalts dui egter nie net op fisiese of waarneembare kragte nie. Dit dien ook as basis vir metaforiese oordrag waarin dié kragte as brondomeine optree wat verhelderend inwerk op nuwe doeldomeine.

'n Vertaler kan bostaande beginsels aanwend om die perspektief van die outeur of verteller (die oorspronklike konseptualiseerder) te analiseer. Hy/sy moet egter ook ag slaan daarop dat die konseptualiseerder ook semantiese verandering kan bewerkstellig deurdat hy/sy hom/haar in 'n bepaalde verhouding tot die proposisie stel ten einde die situasie vir kommunikasiedoeleindes maksimaal volgens sy/haar eie interpretasie en belewing daarvan uit te beeld. Dit gaan dus daarom dat 'n vertaler 'n bepaalde vorm van subjektiwiteit, naamlik die perspektief van die konseptualiseerder, moet kan agterhaal.

\subsection{Perspektief}

Volgens Langacker (1990:6) veronderstel perspektief faktore soos oriëntasie en beheersende punt. Oriëntasie dui op aspekte soos die links-/regs-, voor-/agter-, bo-/onder-oriëntasie van 'n spreker en beheersende punt op die plek waar die spreker staan of kies om te staan ten opsigte van 'n situasie. In hierdie verband word dus nader beweeg aan aspekte van die deiktiese sentrum. 'n Uitdrukking is noodwendig altyd ingebed in 'n bepaalde besigtigingsorganisasie (al die faktore wat die perspektief beïnvloed). Die uitwerking van dié organisasie op die voorkoms van die situasie vorm 'n inherente aspek van die uitdrukking se semantiese waarde. Die beheersende punt wat deur 'n uitdrukking vergestalt word, is direk gekoppel aan die graad van subjektiwiteit of objektiwiteit waarmee 'n konseptualiseerder 'n bepaalde entiteit of situasie konstrueer.

Linguisties beskou, is elke linguistiese uitdrukking of predikasie gekoppel aan 'n konseptualiseerder. Die verskillende aspekte van 
die waarnemingsveld word egter deur die perspektief bepaal wat weer ten nouste saamhang met die begronding.

\subsection{Begronding}

Langacker (1994:5) omskryf begronding soos volg:

... the term ground is used for the speech event, its participants, and its immediate circumstances. The term grounding predication is used for certain elements that relate a profiled 'thing' or process to the ground ...

Begronding sluit die perspektief en deiktiese aspekte in. Die begronding van 'n predikasie moet egter wyer gesien word as net verwysend na 'n taalhandeling plus aspekte soos die tyd wanneer en plek waarop die uiting plaasvind en ook die deelnemers wat betrokke is. Die begronding van ' $n$ predikasie moet noodwendig 'n uitwerking op die semantiese waarde daarvan hê. Die blote feit dat linguistiese uitdrukkings hier ter sprake is, impliseer 'n potensiële gebruiker en daaruit volg dit ook dat die spreker en hoorder ten minste vaagweg bewus moet wees van hulle betrokkenheid in die konstruering van 'n bepaalde konsep. Die mate waartoe hulle betrokke is, mag egter wissel.

Begronding word dus subjektief gekonstrueer en is direk gekoppel aan die posisie van die konseptualiseerder. Langacker (1990:135) stel dit egter duidelik dat die konseptualiseer sy/haar eie posisie kan aanpas:

(I)t is perfectly possible for the speaker, in construing a situation involving himself (or the ground overall) to assume a conceived position in relation to it wherein he can view himself as an objective entity that be observed, discussed, and designated on a par with others.

Die konseptualiseerder kan sy/haar perspektief op dit wat hy/sy waarneem, verander deur sy/haar posisie aan te pas. Insgelyks kan die een wat waargeneem word, ook van posisie verander en sodoende die perspektief op hom/haar verander. Die feit daar daar 'n verhouding tussen die konseptualiseerder en die gekonseptualiseerde is, impliseer beweeglikheid of ten minste potensiële beweging.

In relasionele uitdrukkings word die fokuspunt gevorm deur 'n bepaalde verhouding. Voorbeelde van woordsoorte wat onder hierdie groep val, is adjektiewe, bywoorde, voorsetsels, lidwoorde 
en werkwoorde. In 'n relasionele uitdrukking is daar 'n asimmetrie waarin een deelnemer uitgesonder word as synde dit te wees wat gelokaliseer of vasgestel is en wie se interaksies deur tyd heen gevolg sou kon word. Daar word ook na dié deelnemer verwys as die trajektor. Die trajektor staan teenoor 'n ander opvallende entiteit wat ook bekend staan as die landmerk. In 'n uitdrukking soos "Die man staan voor die struik" sal die man dus as trajektor optree en die struik as die landmerk.

Talmy (1985:297) onderskei ook tussen 'n agonis, die entiteit waarop daar gefokus word en 'n antagonis, die kragelement wat die fokale element opponeer. Omdat kragdinamiese uitings ook as oorsaaklike uitinge beskryf kan word, sluit dit nou aan by relasionele verhoudings: twee entiteite staan in 'n asimmetriese verhouding tot mekaar.

Dié asimmetriese verhouding geld natuurlik ook vir die oorspronklike teks en die vertaalde teks en veral ook die outeur en die vertaler. 'n Duidelik begrip van die konsepte subjektifikasie, perspektief en begronding behoort die aspirantvertaler egter te help in die analise van 'n teks en sou kon bydra tot die opheffing van die asimmetrie (of ten minste dan die verwydering van sekere versperrings) tussen die oorspronklike konseptualiseerder en die aspirantvertaler.

\section{Samevatting}

'n Swak analise van 'n bronteks lei bykans sonder uitsondering tot swak vertalings. Aspirantvertalers vind veral die analise van literêre tekste, onder meer weens die rol wat tydsgees en wêreldbeeld op die perspektief van die oorspronkilike outeur het, problematies. Studente moet leer om hulle eie rol as konseptualiseerders te verstaan en begrip ontwikkel vir die impak wat hulle eie subjektiewe sieninge op 'n teks kan hê. Die kognitiewe linguistiek se hantering van konsepte soos subjektifikasie en perspektief bied aan die opleier van aspirantvertalers 'n nuttige opleidingsinstrument. Dit is veral taalkragdeterminante wat hier van belang is, aangesien 'n vertaler dié beginsels kan aanwend om die perspektief van die outeur of verteller (die oorspronklike konseptualiseerder) te analiseer.

\section{Toepassing: "Voorgevoel" deur John Miles}

Die kort kortverhaal "Voorgevoel" deur John Miles leen hom goed daartoe om die aspekte wat hierbo uiteengesit is, op 'n praktiese wyse vir aspirantvertalers te illustreer. Die teks word geanaliseer deur in die eerste plek te fokus op die rol van die verteller as 
konseptualiseerder. Die optrede van taalkragdeterminante in die teks word vervolgens bespreek. Ten slotte word aangedui hoe die beginsels van kragdinamika ook as metafoor kan optree vir die vertaalproses as sodanig. ('n Moontlike vertaling van die teks word vir volledigheid ook verskaf).

$$
\begin{aligned}
& \text { "Voorgevoel" - John Miles } \\
& \text { [Premonition (pre-feeling)] }
\end{aligned}
$$

1. Ek het die man die straat sien oorsteek van die kafee se kant af. Hy het óór die I saw the man crossing the street from the café. He stepped across the

2. voor getrap, óp na die sypaadjie en moet 'n blomknop of twee sien lê het furrow up onto the pavement and must have seen a flowerbud or two lying -

3. die vorige nag het die wind nogal erg gewaai - want hy het vinnig opgekyk na the night before the wind blew rather badly - because he quickly looked up to

4. my tuin en toe sy oë die groot struik vind, kon ek sien hoe vorm sy lippe die vier my garden and when his eyes found the shrub, I could see his lips forming the four

5. sillabes van kamelia.

syllables of camelia

6. Ek ken sy gesig al. Daagliks kom hy van die kafee se kant af as ek my tee staan I know his face by now. Daily he comes from the cafés side when I stand drinking my

7. en drink, hier voor die venster. En elke keer volg ek sy figuur se stokkerige tea, here, in front of the window. And every time I follow his body's stocky

8. bewegings deur die ou ruit, half onbewus, terwyl ek besig bly met een of ander movements through the old window pane, half unconsciously, whilst occupied with

9. formulering vir my proefskrif. Dis amper 'n soort dwangaksie om so te speel met one or the other formulation for my thesis. It's almost a kind of compulsion to play

10. die distorsies van die ou ruit: Ek draai my kop net baie effens en merk hoe sy with the distortions of the old pane. I turn my head ever so slightly and notice how his

11. voete buite verhouding is met die res van sy lyf; dan dans sy kop weer glaserig feet are in disproportion to the rest of his body; and then again his head dances

12. 'n ent voor sy lyf uit. glassy - clear from his body

13. Maar dié keer het ek my werk geheel en al vergeet: hy ken dus ook die kamelia. But his time I forgot my work completely: he also knows the camelia.

14. Vir wie sou hy werk? Hy was nogal goed versorg. Ek het gewonder of hy Who would he be working for? He was rather well groomed. I wondered whether

15. Sotho of Zoeloe is. En hy ken die kamelia. he was Sotho or Zulu. And he knows the camelia

16. Ek het dadelik besluit om 'n geselsie met hom aan te knoop en het reeds I immediately decided to chat to him and had already turned away from the

17. begin wegdraai van die ruit ..., in my spore verstyf. En net daar bly staan. window ..., stalled in my steps. And remained standing there. 
18. Hy wou net-net by die volgende huis wegraak maar met my effense beweging He was about to disappear behind the next house but with my slight movement

19. van so ewe het hy skielik oor die hele onderkantste helfte van die ruit versprei. of a moment ago he suddenly spread over the bottom half of the pane.

20. Hy't die kamer ingestroom met sy kleur, op my stoele gaan sit, deur die He flowed into the room with his colour, went and sat on my chairs, paged

21. naslaanwerke vir my proefskrif geblaai en gevra of hy sy pyp mag stop. through the reference works of my thesis and asked if hy may stuff his pipe. 1970

\subsection{Analise van die teks}

Die verteller tree op as konseptualiseerder. Die beheersende punt (wat insluit die begronding en die deiktiese elemente) is direk gekoppel aan die posisie van die konseptualiseerder. In ooreenstemming met Langacker (1990:135) neem die konseptualiseerder 'n gestelde posisie in waarin hy homself as 'n objektiewe entiteit in die verhaal in die vorm van die "ek" wat as landmerk optree, waarneem. Hierdie "ek" staan egter in 'n bepaalde verhouding tot "die man" wat as trajektor optree aangesien dit hy is wat gelokaliseer of vasgestel word en wie se interaksies deur tyd heen gevolg word. Die onmiddellike waarnemingsveld hou verband met die tekswerklikheid (die studeerkamer en dit wat deur die ruit sigbaar is) terwyl die breër waarnemingsveld ook die buite-tekstuele werklikheid sal insluit, byvoorbeeld die veronderstelde sosiopolitieke milieu waarin die verhaal afspeel (vgl. Swanepoel, 1988:5558 , vir 'n omvattende bespreking van die bepaalde kulturele waardesisteem in die verhaal). Die verhouding tussen die landmerk en die trajektor is egter uit die staanspoor asimmetries en word nominaal gedra deur onder meer die voornaamwoorde, ek, hy, my, sy, en kragdinamies uitgebou deur onder andere die gebruik van voorsetsels: vergelyk byvoorbeeld reeds die titel Voorgevoel en ook die eerste twee reëls waar die man óór die voor en óp na die sypaadjie trap en dus van die oorkant af na die verteller toe beweeg.

Die taalkragdeterminante in die verhaal kan soos volg uiteengesit gesit word:

- Kompulsie:

r. 9: "'n soort dwangaksie"

- Blokkasie:

r. 10: "die distorsies van die ou ruit"

- Teenwerkende krag

r. 17: "in my spore verstyf. En net daar bly staan" 
- Afwyking:

r. 3-5: "want hy het vinnig opgekyk na my tuin"

- Verwydering van versperring:

r. 19 en 20: "... maar met my skielike beweging van so ewe het hy skielik oor die hele onderkantste helfte van die ruit versprei. Hy't die kamer ingestroom".

- Potensiële krag:

r. 10 en 11:" Ek draai my kop net effens en merk hoe sy voete buite verhouding is met die res van sy lyf ..."

- Aantrekkingskrag:

r. 16: "Ek het dadelik besluit om 'n geselsie met hom aan te knoop ..."

Die verskillende kragte word egter ook onderlê deur twee handelinge: sien en beweeg. Vergelyk die volgende:

\section{Sien}

r. 1: "Ek het die man die straat sien oorsteek"

r. 2: "en 'n blomknop of twee sien lê het"

r. 3: "hy het vinnig opgekyk"

r. 4: "toe sy oë die groot struik vind, kon ek sien hoe vorm sy lippe ..."

r. 7: "En elke keer volg ek sy figuur se stokkerige bewegings"

r. 10: "Ek draai my kop net effens en merk hoe sy voete ..."

\section{Beweeg}

r. 10: "Ek draai my kop net baie effens"

r. 16" "... en het my reeds begin wegdraai van die ruit ..."

Die volg van die trajektor (met ander woorde die kyk na wat die trajektor [die man] raaksien - die kamelia - en hoe hy daarop reageer) lei uiteindelik tot 'n afwyking in die blokkasie waardeur die landmerk (ek) doelbewus besluit om van posisie te verander (hy begin reeds wegdraai). Die versperrings word dus uit die weg geruim deurdat die landmerk van posisie verander (LW: Hy beweeg net twee maal: eers deur sy kop net effens weg te draai en dan deur te begin om weg te draai). 'n Aantrekkingskrag ontstaan dus en dit maak letterlik die deur (ruit) oop vir wedersydse identifisering met die ander se posisie. Die asimmetrie word dus opgehef. (Vergelyk byvoorbeeld die intieme aard van die hy wat op my stoele gaan sit, deur die naslaanwerke van my proefskrif [waarin niemand behalwe ek waarskynlik in geïnteresseerd is nie]) begin blaai en hy wat sy pyp wil stop.) 
Deur die onderskeid tussen landmerk en trajektor te gebruik, is dit moontlik om aan te toon hoe daar vanuit die karakter-fokalisatorvertellersposisie vanuit 'n punt wat buite die strorievlak lê, gekonseptualiseer word. Die verteller verbaliseer nie net sy eie waarnemings nie, maar ook dié van die ander karakter, die swart man. Die sekondêre fokalisator se waarnemings word via dié van die primêre instansie na die leser gereflekteer (Swanepoel, 1988: 55). Deur gebruik te maak van kragdinamiese aspekte is dit moontlik om aan aspirantvertalers ' $n$ instrument te gee om die verhaal te analiseer deurdat dit enersyds die asimmetrie tussen die landmerk en die trajektor aandui, maar ook die beweging van die krag wat uiteindelik die asimmetrie ophef, uitwys. Die konsepte onmiddellike en breër waarnemingsveld kan ook bydra tot die aspirantvertaler se begrip van die teks. Sy moet kan sien wat die verteller sien - nie net deur die ruit nie, maar ook wyer en buite die teks. Om die teks te verstaan moet sy ook die kultureel-ideologiese onderbou van die teks onder die knie kry.

\subsection{Implikasies vir die vertaalproses}

Naas die gebruikmaking van kognitiewe semantiek as 'n instrument in die analisering van die bronteks, kan die konsepte konseptualiseerder, landmerk, trajektor, onmiddellike en breër waarnemingsvelde, asook die werking van taalkragdeterminante as metafoor dien om aan aspirantvertalers ' $n$ duidelike beeld van die vertaalproses te gee.

In die vertaalproses neem die vertaler die posisie van konseptualiseerder in, die doelteks kan as die trajektor en die bronteks as landmerk beskou word. Die talige en kulturele aspekte sou deel uitmaak van die onmiddellike waarnemingsveld van die konseptualiseerder terwyl die breër waarnemingsveld die volledige vertaaltradisie en -teorie inkorporeer.

Die vertaalopdrag sou as kompulsie beskou kon word, blokkasie sou kon dui op bepaalde gebreke in die vertaler se mondering, byvoorbeeld 'n onvermoë om 'n teks behoorlik te kan analiseer. Die vertaler se eie subjektiewe konseptualisering van die mentale ervaring kan as teenwerkende kragte beskou word. Afwyking dui op die moontlikheid dat uitdrukkings wat dieselfde objektiewe situasie en dieselfde konseptuele inhoud oordra, nietemin semanties heelwat kan verskil - iets waarop die vertaler altyd bedag moet wees. Die verwydering van versperring dui op die vind van 'n geskikte vertaalstrategie om 'n bepaalde versperring mee uit die weg te ruim, en potensiële krag op die moontlikheid om altyd 'n meer geskikte 
vertaalekwivalent te vind. Aantrekkingskrag kan in hierdie sin gesien word as die bereiking van die uiteindelike doel van die vertaling, naamlik die opheffing van 'n asimmetriese verhouding tussen die bron- en doelteks, of dan ekwivalensie.

\section{Gevolgtrekking}

Die kognitiewe semantiek hou nie alleen interessante moontlikhede in vir die bestudering van literêre tekste (vgl. Pienaar, 1996) nie, maar die beginsels soos hierbo geïllustreer, is ook van toepassing op die wyse waarop ' $n$ vertaler 'n teks behoort te benader. Dit kan ook as metafoor gebruik word om die vertaalproses aan aspirantvertalers te verduidelik.

Tabakowska (2003:225) stel byvoorbeeld dat

In a literary text the induced reader attention comes as the result of the author's choice, and maintenance, of a particular point of view. One of the basic categories of literary theories, in cognitive linguistics POV (point of view) has been discussed in terms of the semantic opposition between objectification and subjectification.

Die vertaler moet kennis neem van die outeur se keuse, instandhouding en verandering van 'n spesifieke perspektief (en begronding) en moet as 't ware dieselfde posisie kan inneem in die analise van die teks met die oog op die vertaling daarvan. Kennis van die werking van objektivering en subjektifering en die wyse waarop taalkragdeterminante onder meer hierdie opposisie rig, kan veral die aspirantvertaler help om die posisie van die verteller beter te verstaan, in stand te hou, te volg indien dit verander en uiteindelik akkuraat in die vertaling weer te gee.

Begrip van die beginsels van kragdinamika behoort dit vir 'n aspirantvertaler moontlik te maak om haar eie rol as konseptualiseerder duideliker te verstaan en kan bydra tot 'n bepaalde vereenselwiging of opmekaarplasing van die perspektief van die outeur enersyds en die van dié vertaler andersyds.

\section{Geraadpleegde bronne}

BUSH, P. 2001. Literary translation. (In Baker, M., ed. Routledge Encyclopedia of translation studies. London/New York: Routledge. p. 127-130.)

GIBBS, R.W. 1999. Researching metaphor. (In Cameron, L. \& Low, G., eds. Researching and applying metaphor. Cambridge: Cambridge University Press. p. 29-47.) 
JOHNSON, N. 1987. The body in the mind. The bodily basis of meaning, imagination and reason. Chicago: University of Chicago Press.

KENNY, D. 2001. Equivalence. (In Baker, M., ed. Routledge Encyclopedia of translation studies. London/New York: Routledge. p. 77-80.)

LANGACKER, R.W. 1990. Subjectification. Cognitive Linguistics, 1(1):5-38.

LANGACKER, R.W. 1994. Viewing in cognition and grammar. Unpublished conference hand-out. 19th International LAUD Symposium on 'Language and Space'. Duisburg.

LANGACKER, R.W. 2002. Deixis and subjectivity. (In Brisard, E., ed. Cognitive linguistic research 21: Grounding. The epistemic footing of deixis and reference. Berlin/New York: De Gruyter. p. 1-28.)

MONDAY, J. 2001. Introducing translation studies. Theories and applications. London/New York: Routledge.

NEWMARK, P. 1995. A textbook of translation. New York: Phoenix ELT.

PIENAAR, M. 1996. Subjektifikasie en metaforiek: Struktureringsmeganismes in (drama)diskoers, met verwysing na Christine deur Bartho Smit. Johannesburg: Randse Afrikaanse Universiteit. (D. Litt. et Phil.-proefskrif.)

POTGIETER, M.K.A. 2003. Die verrekening van 'n tydsgees in die vertaling van die sprokies van Herman Hesse. Johannesburg: Randse Afrikaanse Universiteit. (M.A.-verhandeling.)

STRYDOM, L. 1994. Taalkragdeterminante in die drama Leuens deur Corlia Fourie. Johannesburg: Randse Afrikaanse Universiteit. (M.A.verhandeling.)

SWANEPOEL, E. 1988. Aspekte van fokalisering in die bundel Liefs nie op straat nie van John Miles. Stellenbosch: Universiteit van Stellenbosch. (M.A.-verhandeling.)

TABAKOWSKA, E. 1993. Cognitive linguistics and poetics of translation. Tübingen: Gunter Narr Verlag.

TABAKOWSKA, E. 1997. Image in translation. A case of three Polish Hamlets. (In Smieja, B., Tasch, M., eds. Human contact through language and linguistics. Duisburg Papers on research in Language and Culture 31. Frankfurt: Lang. p. 167-186.)

TABAKOWSKA, E. 2003. Subjectification of meaning in a (literary) text. (In Abstracts of 8th conference of the Cognitive Linguistics Association on "Cognitive linguistics, functionalism, discourse studies: Common ground and new directions". Longono, Spain: International Cognitive Association. p. 225.)

TALMY, L. 1985. Force dynamics in language and thought. (In Papers from the parasession on Causatives and Agentivity at the twenty-first regional meeting of the Chicago Linguistic Society. Chicago: Chicago Linguistic Society. p. 293-337.)

TALMY, L. 2000. Towards a cognitive semantics. Cambridge: MIT.

\section{Kernbegrippe:}

subjektifikasie

taalkragdeterminante

teksanalise in literêre vertaling 


\section{Key concepts:}

force dynamics

subjectification

text analysis in literary translation 